\title{
Exploring the determinants of Internet continuance intention and the negative impact of Internet addiction on students' academic performance
}

\author{
Mahmoud Maqableh $^{\mathrm{a}^{*}}$, Ahmad Obeidat ${ }^{\mathrm{b}}$ and Zaid Obeidat ${ }^{\mathrm{c}}$
}

${ }^{a}$ Department of Management Information Systems, School of Business, University of Jordan, Amman 11942, Jordan

${ }^{b}$ Department of Business Administration, School of Business, The University of Jordan, Amman 11942, Jordan

${ }^{c}$ Department of Marketing, School of Business, The University of Jordan, Amman 11942, Jordan

\section{H R O N I C L E}

Article history:

Received: March 18, 2021

Received in revised format: April

18, 2021

Accepted: June 28, 2021

Available online: June 28, 2021

Keywords:

Emotional value

Perceived image

Satisfaction

Continuance intention

Academic performance

Internet addiction

Internet

\section{A B S T R A C T}

\begin{abstract}
This study aims to investigate the impact of integrating essential factors on Internet usage continuance intention in students' context. The proposed model examines the influence of perceived enjoyment, perceived image, satisfaction, information value, and emotional value on Internet continuance intention. Additionally, it investigates the role of Internet addiction, satisfaction, and continuance intention on academic performance among university students. A survey questionnaire method was adopted to collect data from university students in Jordan. Data was collected from 450 voluntary participants, and the analysis was conducted using SPSS and AMOS. The analysis results show that perceived enjoyment, perceived image, information value, and emotional value have a significant positive influence on continuance intention of Internet use. Besides, the results show that continuance intention has a positive impact on satisfaction and Internet addiction. While continuance intention has a significant positive impact on students' academic performance, and Internet addiction has a significant negative impact on students' academic performance, the impact of satisfaction on academic performance was not supported. This study is the first to examine integrating of perceived enjoyment, perceived image, information value, and emotional value on Internet continuance usage. Furthermore, this study is also distinguished from other studies by investigating the negative impact of Internet addiction on students' academic performance gap.
\end{abstract}

\section{Background}

Nowadays, Internet resources have become a very important component in educational systems (Salam and Farooq 2020). University students are using the Internet daily for several purposes such as accessing course materials and searching for information (Bagavadi Ellore et al. 2014). Furthermore, most people are using the Internet for entertainment. Currently, the Internet is considered as an essential learning tool for all students (Al-Fraihat et al., 2020). In January 2021, it was reported that daily time spent on social networking by internet users worldwide is on average around two hours and 45 minutes (Statista 2021). Over the past few years, many researchers examined the determinants of continuance intention to use Internet and social media sites (Joorabchi et al., 2011; Karnik et al., 2013; Houghton et al., 2020; Marengo et al. 2020). The impact of using Internet and technology tools on students' academic performance has been examined in the literature (Choi, 2016; Naqshbandi et al., 2017; Bae, 2018; Hou et al., 2020). A research study examined the mediating role of Facebook on the relationship between different personality dimensions and academic performance (Naqshbandi et al., 2017). Other research examined the role of entertainment, satisfaction, and enjoinment as the antecedents of continuance intention to use Internet

* Corresponding author. Tel: +962 65355000 , Ext. 24247

E-mail address: maqableh@ju.edu.jo (M. Maqableh)

(C) 2021 by the authors; licensee Growing Science, Canada. doi: $10.5267 /$ j.ijdns.2021.6.014 
(Basak \& Calisir, 2015; Choi, 2016; Bae, 2018) are among the many antecedents evidenced in the literature. In 2020, a research group from China investigated the impact of social media (WeChat) on students' academic performance (Hou et al. 2020). The research results confirmed the positive impact of social media on students' academic performance as it enhances students' engagement, information, and resources sharing. The impact of students' interaction with different online learning activities on learning performance has been examined (Çebi \& Güyer 2020). The research results confirmed that spending longer time on learning activities enhances their academic performance. Some research studies classified the technology adoption and use of drivers into individual drivers such as perceived enjoyment, information value, and emotional value and social drivers such as perceived image and subjective norm (Skog, 2009; Mohammadi, 2015; Zhang et al., 2017).

The purpose of this study is to investigate the impact of integrating essential factors (perceived enjoyment, perceived image, information value, and emotional value) that influence continuance usage intention of the Internet in students' context. Additionally, it investigates how continued intention to use the Internet influences satisfaction and Internet addiction in the context of university students. Moreover, it examines the impact of Internet addiction, satisfaction, and continuance intention on students' academic performance. This study is the first to examine the relationship between integrating four essential factors and continuance intention to use the Internet. Additionally, it is distinguished from other studies through investigating the role of Internet addiction on students' academic performance gap.

\section{Literature Review and hypotheses development}

\subsection{Continuance intention}

Many research studies examined the users' initial intention to use technology (Bölen, 2020; Maqableh et al., 2021). It is essential to also explore and understand the continuance intention to use technology, as the initial intention to use technology is not adequate. Continuance intention refers to the strength of an individual who intends to perform a specific activity (Amoroso \& Lim 2017). There are some factors that would encourage users to stay loyal and continue using the technology (Kang, 2019; Wang et al., 2020). Many researchers examined the factors that influence users' continuance intention to use technology. Research and educators need to understand (Authors et al., 2016; Kang, 2018; Pai et al., 2018). Nowadays, the Internet has already surpassed us as the main source of information for users. Thus, it is necessary to conduct exploratory research to identify and measure the factors affecting continuance intention to use Internet. In this study, continuance intention refers to Internet usage continuance intention. Many studies examined the initial intention to use technology in the information system (IS) literature based on different theories (Alshurideh et al., 2021; Maqableh et al., 2021). Some studies focus on understanding the factors that increase users' continuance intention and its impact on loyalty (Alzougool, 2019; Bölen, 2020). Additionally, literature directed towards understanding the continuance use of technology is growing (Authors et al., 2016; Pai et al., 2018; Bölen 2020). However, the Internet is rich in cases for studying as they have high levels of interactions between users and would help researchers to explore better the different factors that affect continuance intention to use technology (Gao et al., 2014; Fang \& Liu, 2019). Consequently, it is necessary to do exploratory research to identify and measure factors affecting continuance intention to use Internet sites. Overall, Continuance intention previously has mainly been examined in the literature as dependent variable literature (Yang, 2019; Zong et al., 2019). However, we will examine its relationship with satisfaction, Internet addiction and students' academic performance.

\subsection{Perceived enjoyment}

Pursuing fun and pleasure from using the internet is linked with the enjoyment that will motivate users, and shape their behaviours and attitudes (Kuan-Yu \& Hsi-Peng, 2011; Huang, 2020). However, users' privacy concern and lack of control affect their enjoyment (Zhou, 2015). In addition, larger networks are found to increase users' benefits and utility and allow for more choices of communication to enhance network benefits (such as online gaming and online auction) (Zhao \& Lu, 2012). Numerous researchers (e.g. Davis et al., 1992; Kim, 2011; Mouakket, 2015; Huang 2020) viewed perceived enjoyment as an intrinsic motivator. According to Davis et al. (1992), perceived enjoyment refers to the degree to which an activity is perceived as being enjoyable irrespective of any expected consequences. Kim (2011) stated that intrinsic motivation is the perceived joy or pleasure from performing an activity and that it is captured by perceived enjoyment. Furthermore, Kim (2011) notes that it is an important post-adoption belief by the user leading to increased levels of continuance intention. Previous research has examined the relationship between perceived enjoyment and continuance intention to use different types of technologies and services and found a positive relationship between the two constructs (Kim, 2011; Sun et al., 2014; Choi, 2016; Fang \& Liu 2019). Choi (2016) found that continuance intention to use smartphone-based social network sites was positively and significantly determined by enjoyment. Mouakket (2015) found that enjoyment has a positive impact on the user's intention to continue using social network sites (i.e., Facebook). Similarly, Kim (2011) found that perceived enjoyment was a significant predictor of a user's continued intention to use social network sites. Shiau and Luo (2013) found that perceived enjoyment was significantly related to continuance intention to use blogs. Kim (2010) Found that perceived enjoyment was significantly related to continuance intention to use mobile data services. (Al-Maghrabi \& Dennis 2011) found that perceived enjoyment was positively related to customer's continuance intention to use e-shopping. Fang and Liu (2019) found that perceived enjoyment has a significant positive impact on continuance intention of mobile users. 
Based on the previous arguments, it is expected that when a user enjoys using the internet, he/she will be more intrinsically inclined to continue using the internet. Thus, the following hypothesis is proposed:

\section{$\mathbf{H}_{1}:$ Perceived enjoyment significantly influences continuous intention to use the Internet.}

\subsection{Perceived image}

The perceived image can be defined as how the use of a specific service/product enhances the user's image or social status (Mohammadi, 2015; Ofosu-Ampong et al., 2020). According to Revels et al. (2010), the perceived image refers to the extent to which the use of the Internet increases a person's image or social status. Some studies showed that perceived image could be considered as one of the social drivers for technology adoption and use (Skog, 2009; Matson et al., 2012; Mohammadi, 2015). Several studies have empirically examined the relationship between perceived image and continuance intention. Mohammadi (2015) found that perceived image had a significant positive effect on intentions to use m-learning. External and internal factors (such as social environment, the participation of friends and family, interests, attitude, physiological and psychological state of the users) can affect users image, for example Chen et al. (2012) discussed that social environment of the Web 2.0 has a significant influence on the intention to use the service continuously. They argue that the user's perceived image boosted from using a service may result in the user deciding to use that service continually. The results showed that perceived image had a significant positive effect on continuance intention to use Web 2.0 applications. Furthermore, participation in social media can be influenced by the enhancement of self-esteem and status, which is found to affect continuous intention (Basak \& Calisir 2015). They argue that the enhancement of the self-esteem and status of individuals is facilitated by their participation in social media. Also, Basak and Calisir (2015) found that status seeking (that is, enhanced social status) had an indirect significant effect on continuance intention to use Facebook. Based on the previous arguments, it is expected that individuals will experience continuance intention to use the internet because they are motivated by a desire to enhance their self-image and social status. Thus, the following hypothesis is proposed:

\section{$\mathbf{H}_{2}$ : Perceived image significantly influences continuous intention to use the Internet.}

\subsection{Information value}

Some research studies proposed another antecedent to continuous usage of an IT product/service is perceived usefulness which is closely related to information value (Zhang et al., 2017; Yang et al., 2018; Wang et al., 2020). The benefit from acquiring useful information through using the internet determines information value, especially if the information helps the user to solve problems of developing his skills and abilities (Zhang et al., 2017). The uses and gratifications theory (U\&G theory) explains why users select and adopt certain mediums to fulfil their social and psychological needs (Ku et al., 2013; Ma \& Lee, 2012). This theory has been linked with continuous intention, factors that satisfy users' gratification needs, such as information needs and social needs. As found by Wei et al. (2015), those two needs are critical factors to motivate users to interact with each other and in turns enhance their stickiness towards using social networking sites. Moreover, Chiang (2013) found that informativeness, social interactivity and playfulness needs affect users' continuance intention towards social networking sites. Information value refers to the useful information acquired from friends or information providers (Zhang et al., 2017). Chiang (2013) argues that website informativeness is a potential influence on a user's intentions and behaviours. (Liao \& Shi 2017) found that web content (i.e. the accuracy, usefulness and completeness, and website information) has a direct positive influence on the continuance intention to use online tourism services. Zheng et al. (2013) found that information quality has a direct effect on user satisfaction which in-turn influences a user's continuance intention to use information-exchange virtual communities. Similarly, Valaei and Baroto (2017) found that information quality had a positive impact on continuance intention to follow a government's Facebook page. Jin et al. (2007) found that information usefulness positively and significantly affects the continuance intention of virtual communities for information adoption. Based on these results and arguments, the following hypothesis is proposed:

\section{H3: Information value significantly influences continuous Intention to use the Internet.}

\subsection{Emotional value}

Emotional value refers to the satisfaction and emotional comfort that the user obtained from online interaction and support (Zhang et al., 2017). It has a social-psychological dimension which triggers specific feelings or affective states (Sheth et al., 1991). Emotional value is driven by perceived relaxation and perceived playfulness. Therefore, users surf the internet or social networking sites to relax and enjoy themselves (Yang \& Lin, 2017). According to Yang and Lin (2017), emotional value (especially perceived relaxation) is an important determinant of continued intention as it helps users to pass the time and relax. Moreover, previous research associated emotional value with consumers' decision-making process (Wang et al. 2013). Consumption values (such as functional, social, emotional, and epistemic value) are found to affect behavioural intention. They argued that user intention is related to the perceived enjoyment and emotional fulfilment (playfulness, enjoyment, and fun) gained by using mobile applications (Wang et al. 2013). The positive effect of emotions increases an individual's continuance intention to use technology (Yin et al., 2015; Yang et al., 2018). Empirical evidence provides support to this 
notion. For example: (Yang \& Lin 2017) found that emotional value (i.e. perceived relaxation) had a positive effect on the continuance intention to use SoLoMo services. Moreover, Lee and Kwon (2011) found that intimacy and familiarity (affective factors) positively influenced continuance intentions to use web-based services. Based on these arguments, the following hypothesis is proposed:

\section{$\mathbf{H}_{4}$ : Emotional value significantly influences continuous Intention to use the Internet.}

\subsection{Academic performance}

Academic performance is defined as the ability of students to carry out academic tasks, and it measures their achievement across different academic subjects using objective measures such as final course grades and grading point average (Busalim et al., 2019; Anthonysamy et al., 2020). Researchers agree that the Internet is becoming more important for students. For example (Bagavadi Ellore et al. 2014) note that the Internet is an important part of the life of college/university students. Similarly, Naqshbandi et al. (2017) note that most students use Facebook daily, making it a significant component of their daily lives. Many studies confirm the benefits that Internet users provide for students. For example: (Mccamey et al. 2015) argue that as a result of the expansion of the Internet, college students are increasingly having more resources available to help them widen their knowledge. Similarly, Emeka and Nyeche (2016) argue that the Internet is beneficial for students in that it enhances their capabilities and skills which are helpful in their studies, which is used by students for research purposes, assignments, and presentations in their respective fields of study. Several studies have examined the relationship between using the Internet's resources/services and academic performance of different foci. For example: (Sampath Kumar and Manjunath 2013) found that university teachers and researchers' use of Internet sources and services had a positive impact on their academic performance. Emeka and Nyeche (2016) found that the use of the Internet has a positive influence on the academic performance of undergraduate students in a university in Nigeria. Based on these arguments, it is expected that students' continuance intention to use the Internet and its resources will help them improve their academic performance. Thus, the following hypothesis is proposed:

\section{H5: Continuous intention to use Internet significantly influences students' academic performance.}

\subsection{Satisfaction}

User satisfaction refers to the general feeling of fulfilment because of using the internet (Patwardhan et al., 2011). Satisfaction is an old but contemporary construct that has been used by many researchers in different disciplines (Ki Hun Kim et al., 2019). It has been used in the work context to measure job satisfaction (Locke 1976) (Saari and Judge 2004) and in the organizational context to customer satisfaction (Oliver \& Gerald, 1981; Barrett, 2004). Satisfaction is measured in the IS literature as well as many theories have been deployed accordingly. An Expectation-Confirmation Model of continued IT usage (ECM-IT) developed by Bhattacherjee (2001), this model compares user continued IT decisions to consumer repeat purchase decisions. The research found that continuous usage of an IT has three antecedents, one of which is satisfaction with the IT used (Odel $\&$ Bhattacherjee 2001). Chen et al. (2009) found that consumers' satisfaction positively and significantly influences continuance intention to use self-service technologies (Chen et al. 2009). In relation to the reuse of health information, Kim (2010) found that customer satisfaction had a significant positive influence on the decision to reuse health information provided by the internet (Kyoung Hwan Kim, 2010). Bae (2018) found satisfaction with social network sites to have a significant impact on continuance intention to use social network sites (Bae, 2018). Based on the Expectation Confirmation Model (EDM), satisfaction is analyzed to understand the relationship between satisfaction and experiences while using technology (Melone, 1990; Bhattacherjee, 2014); customers usually expect the performance of a product or a service before the actual usage. If their expectations match their experience, then they would be satisfied. Therefore, the positive customer experience at first glance is a crucial determinant of user satisfaction. (Kuo et al., 2009) suggested that satisfaction can also be the aggregated positive emotional states developed through several experiences with the product or the service. Users' IT continuance use behaviour is positively influenced by their satisfaction with prior IT usage (Bhattacherjee \& Lin 2015). The uses and gratification theory is also performed as a theoretical basis to ground a better understanding of satisfaction and its relationship with continuance intention to use social networking systems. Chiu and Huang (2015) revealed that user satisfaction with contents and features of social networking systems had a positive relationship with continuance use. Based on the significant influence of satisfaction on continuance usage intention, the following hypothesis is proposed:

H6: Continuous intention to use Internet significantly influences satisfaction.

$\mathbf{H}_{7}$ : Satisfaction significantly influences students' academic performance.

\subsection{Internet addiction}

Facebook addiction refers to the excessive use of Facebook due to being psychologically reliant on its use in a way that somewhat hinders other essential actions that the user could perform and, in the process, yielding negative results (Moqbel \& Kock, 2018). There are about 350 million Facebook users between 16 and 25 years old showing Facebook addiction syndrome (Leong et al., 2019). Overall, previous literature has mainly examined the concept of continuance intention as a dependent 
variable (Yang \& Lin, 2014; Yang et al., 2018; Yang, 2019; Zhang et al., 2017; Zong et al., 2019). However, we will examine its relationship with Facebook addiction. Generally, numerous theories and findings have established the relationship between behavioural intention and actual behaviour (Obeidat et al., 2017; Pelling \& White 2009; Turel et al., 2010). Consequently, if the continuance intention of Facebook use is present, the user will continue to do so, thereby increasing the chances of addiction to the website. Furthermore, previous studies found that when a certain behaviour is exhibited, and the person is willing to do it again, future behaviour becomes an automatic, aligned response (Ronis et al., 1989). Therefore, the more a person uses social media to communicate with others, the more likely it will become a habit and lead to addiction (Turel et al. 2010). (Chen et al., 2008) conducted a research study that confirms higher Internet addiction can lead to a high degree of Internet abuse. Also, Samaha and Hawi (2016) conducted a research study that showed smartphone addiction had a negative impact on students' academic performance.

Following the same logic, we propose that the Facebook continuance intention resulting from the perceived values will increase Facebook addiction. Thus, this study is the first study that investigates the relationship between continuance intention and addiction gap. Generally, this factor was found to strongly influence the association between online purchase intention and actual behaviour (Miyazaki and Fernandez 2001; Nepomuceno et al. 2014). Thus:

H8: Continuous intention to use Internet significantly influences Internet addiction.

H9: Internet addiction significantly negative influences on students' academic performance.

\section{Research Methodology}

This section provides the methodology applied in the current study. It consists of the research model of the study's independent and dependent variables, research hypotheses, besides data collection tool and research population and sample.

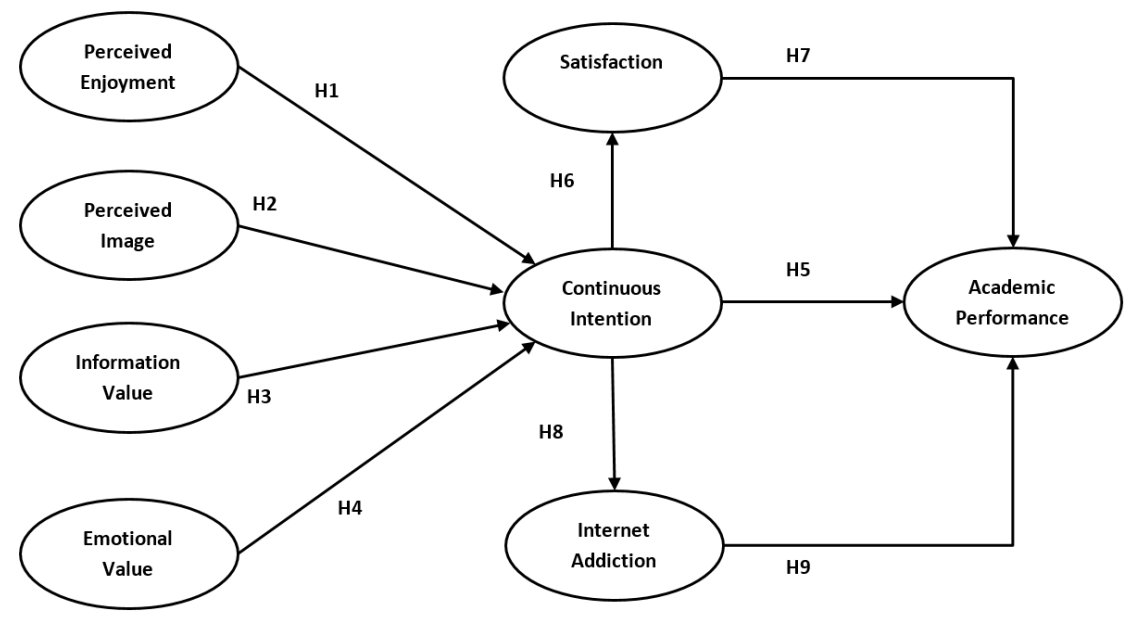

Fig. 1. Research model

\subsection{Research Model}

In this research, we propose a new model based on extending the associations between individual drivers and social drivers by investigating the relationship between enjoyment, perceived image, satisfaction, information value, and emotional value on Internet continuance intention. Moreover, it investigates the impact of continuance intention, satisfaction, and Internet addiction on students' academic performance gap. Fig. 1 shows the proposed research model.

\subsection{Data collection and sample}

Data were collected from targeted participants with Internet experience using an online survey. Participants were selected opportunely from 4,000 bachelor students from the School of Business at the University of Jordan in the Hashemite Kingdom of Jordan. However, what constitutes an adequate sample size for regression analysis is uncertain among researchers. Some researchers (O'Rourke \& Hatcher, 2013) recommend that the sample size of a study that applies multiple linear regression should be 100 participants or more than five times the number of items measured. The questionnaire was made up of 22 items, so the sample size should be over 160 students. Also Hair et al. (2014) recommended between 100 and 200 while Krejcie and Morgan (1970) required 351 from a population of 4,000. Therefore, the number of returned surveys is 450 that meet the requirement of sample size for a structural equation model and show adequate representation with the highest probability assessment. In Fig. 2, the respondents' characteristics of this study are summarized. 


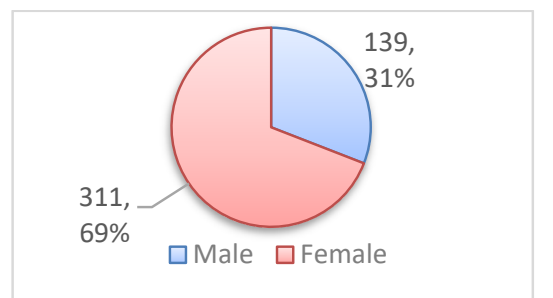

Gender

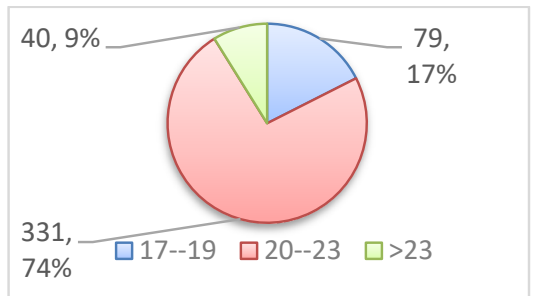

Age

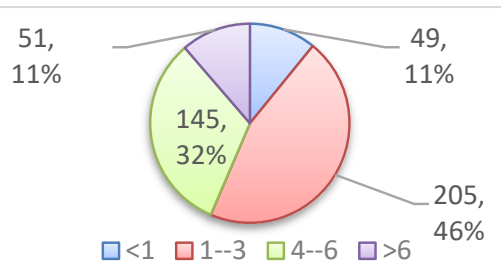

Internet usage per day (Hours)

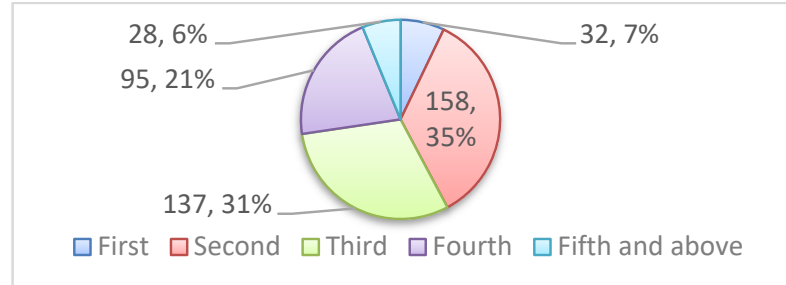

Academic level

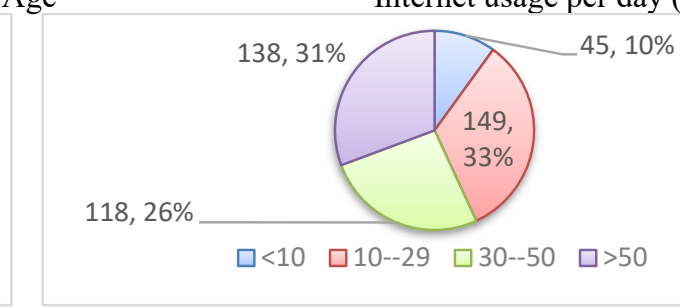

Internet usage per week (Hours)

Fig. 2. Characteristics of the research sample $(n=450)$

The 450 valid responses comprised $69.1 \%$ female students. The dominant age range in the sample was 20 to 23 years, with a percentage of $73.6 \%$. The respondents were mainly in their second and third years at the university with a percentage of $65.5 \%$ of the sample. $45.6 \%$ of students spend 1 to 3 hours daily on internet activities. Moreover, almost 33\% use the internet from 10 to 29 hours weekly. The full respondent's profiles are shown in Fig. 2.

\subsection{Measurement development}

To explore the associations among the research variables, in which these variables have been measured using the 5-points Likert scale that varies between strongly disagree $=1$ and strongly agree $=5$. Reliability and validity analyses were conducted, descriptive analysis was used to describe the characteristics of the sample and the respondent to the questionnaires besides the independent and dependent variables. Also, SEM analysis was employed to test the research hypotheses. Table 1 shows the measured constructs and the items measuring each construct.

\section{Table 1}

Constructs and measurement items

\begin{tabular}{|c|c|}
\hline Construct & Measurement Items \\
\hline Perceived Enjoyment (PE) & $\begin{array}{l}\text { EN1: Using the Internet is enjoyable. } \\
\text { EN2: Using the Internet is not boring. } \\
\text { EN3: Using the Internet is interesting. } \\
\text { EN4: Using the Internet is fun. }\end{array}$ \\
\hline Perceived Image (PI) & $\begin{array}{l}\text { PI1: Using the Internet improves my self-image. } \\
\text { PI2: Users who use the Internet have more prestige. } \\
\text { PI3: Users who use the Internet are trendy. } \\
\text { PI4: Users who use the Internet are information technology savvy. }\end{array}$ \\
\hline Satisfaction (SA) & $\begin{array}{l}\text { SA1: I was very content with the Internet. } \\
\text { SA2: I was very pleased with the Internet. } \\
\text { SA3: I felt delighted with the Internet. } \\
\text { SA4: Overall, I was satisfied with the Internet. }\end{array}$ \\
\hline Information Value (IV) & $\begin{array}{l}\text { IV1: I accumulate numerous knowledge through shared information by Internet users. } \\
\text { IV2: I acquire a variety of information from online people using the Internet. } \\
\text { IV3: I obtain lots of useful information from online people using the Internet. } \\
\text { IV4: Over the last one month, I consulted online people using the Internet for practical issues and matters. }\end{array}$ \\
\hline Emotional Value (EV) & $\begin{array}{l}\text { EV1: I receive adequate emotional concern from people using the Internet. } \\
\text { EV2: I feel relieved by getting sympathy from online people using the Internet. } \\
\text { EV3: I have been encouraged by friends on the Internet. }\end{array}$ \\
\hline Continues Intention (CI) & $\begin{array}{l}\text { CI1: If could, I will continue using the Internet. } \\
\text { CI2: I will recommend my friends and family members to use the Internet. } \\
\text { CI3: I will continue using the Internet in the future. } \\
\text { CI4: I intend to continue using Internet service rather than any alternative. }\end{array}$ \\
\hline Academic Performance (AP) & $\begin{array}{l}\text { AP1: I am confident I have adequate academic skills and abilities. } \\
\text { AP2: I feel competent in conducting my course assignment. } \\
\text { AP3: I have learned how to do my coursework efficiently. } \\
\text { AP4: I have performed academically as I anticipated I would. }\end{array}$ \\
\hline
\end{tabular}

Table 2

Standardized factor loading and Cronbach's alpha result 


\begin{tabular}{|c|c|c|}
\hline Item & Standardized Factor loading & Cronbach's Alpha \\
\hline Perceived image A1 & .801 & \multirow{3}{*}{0.676} \\
\hline Perceived image A2 & .671 & \\
\hline Perceived image A3 & .549 & \\
\hline Enjoyment A5 & 0.864 & \multirow{4}{*}{0.783} \\
\hline Enjoyment A6 & 0.685 & \\
\hline Enjoyment A7 & 0.659 & \\
\hline Enjoyment A8 & 0.592 & \\
\hline Information Value A9 & 0.692 & \multirow{3}{*}{0.853} \\
\hline Information Value A10 & 0.921 & \\
\hline Information Value A11 & 0.839 & \\
\hline Emotional Value A13 & 0.790 & \multirow{3}{*}{0.739} \\
\hline Emotional Value A14 & 0.786 & \\
\hline Emotional Value A15 & 0.548 & \\
\hline Academic Performance A17 & 0.852 & \multirow{3}{*}{0.776} \\
\hline Academic Performance A18 & 0.822 & \\
\hline Academic Performance A19 & 0.559 & \\
\hline Satisfaction A20 & 0.649 & \multirow{4}{*}{0.900} \\
\hline Satisfaction A21 & 0.813 & \\
\hline Satisfaction A22 & 0.922 & \\
\hline Satisfaction A23 & 0.885 & \\
\hline Continues Intention A24 & 0.629 & \multirow{4}{*}{0.820} \\
\hline Continues Intention A25 & 0.781 & \\
\hline Continues Intention A26 & 0.837 & \\
\hline Continues Intention A27 & 0.688 & \\
\hline Internet Addiction A31 & 0.552 & \multirow{6}{*}{0.835} \\
\hline Internet Addiction A32 & 0.653 & \\
\hline Internet Addiction A33 & 0.680 & \\
\hline Internet Addiction A34 & 0.725 & \\
\hline Internet Addiction A35 & 0.760 & \\
\hline Internet Addiction A36 & 0.688 & \\
\hline Model fit summary: $\chi^{2} / \mathrm{df}=1$ & & \\
\hline
\end{tabular}

\section{Data analysis and results}

\subsection{Validity and reliability}

To validate the research instrument, confirmatory factor analysis (CFA) was used to assess the scale validity using SPSS 20.0 and AMOS 22.0 since all the measures were previously established. The standardized factor loading of the item was examined. Any item with standardized factor loading less than 0.55 was eliminated, since 0.55 represents a good fit (Harrington 2009). First, the outliers were removed from the data set. 90 respondents were indicated as outliers according to Mahalanobis distance criteria (Garson 2012). This procedure resulted in eliminating items A4 (from Image), A12 (from Information), (A16 from Academic) and A28, A29 and A30 (from Addiction) from the scale. The full-standardized factor loading results from the CFA are presented in Table 2. The model fit was assessed based on the model fit of the summary results. The cut points used in this research were $\mathrm{c}^{2} / \mathrm{df}<5$, Root Mean Square of Error Approximation (RMSEA) $<0.08$, while all the other indices (i.e. GFI, CFI, TLI, IFI and NFI) should be close to 1 where higher than 0.9 is acceptable (Harrington 2009). Results are shown in Table 2. To check the reliability of the scale Cronbach's-Alpha test was used to assess the internal consistency the cut point usually used in research is 0.7, but it can be lowered to 0.6 (Hair et al. 2014). Cronbach's-Alpha results in this research ranged between 0.676 , and 0.900 full results are presented in Table 2. To eliminate the issue of common method bias Harman's one-factor test was used. This test requires that all the scale items are entered in exploratory factor analysis (EFA)using principal component analysis and un-rotated factor solution, no single factor should account for more than $50 \%$ of the variance (Podsakoff \& Organ 1986). In this research, a single factor was responsible for $20.897 \%$ of the variance; this suggests that common method bias is not an issue.

\subsection{Descriptive statistics and correlations}

According to the person correlations in Table 3, none of the demographics was found to influence the dependent variables except for the academic performance, where the number of Using the Internet (Hours per week) was found to have a significant negative correlation with academic performance $(\mathrm{r}=-0.157, \mathrm{p}<0.01)$. Regarding the descriptive statistics, the highest mean score was for enjoyment (3.85) which indicates a high positive respondents' attitude toward the Information, followed by value enjoyment (3.84). At the same time, the lowest mean score was for satisfaction (2.30). All the variables Skewness and Kurtosis values were within the limit of -1 to +1 , which indicates normality(Garson 2012). The full results are furnished in Table 4. 
Table 3

Person correlations

\begin{tabular}{|c|c|c|c|c|c|c|c|c|c|c|c|c|c|c|}
\hline & & 1 & 2 & 3 & 4 & 5 & 6 & 7 & 8 & 9 & 10 & 11 & 12 & 13 \\
\hline 1 & Gender & 1.00 & & & & & & & & & & & & \\
\hline 2 & Age & $-.196 \#$ & 1.00 & & & & & & & & & & & \\
\hline 3 & Level & $-.162 \#$ & $.635 \#$ & 1.00 & & & & & & & & & & \\
\hline 4 & Daily & 0.08 & -0.02 & -0.02 & 1.00 & & & & & & & & & \\
\hline 5 & Weekly & -0.04 & 0.02 & -0.02 & $.531 \#$ & 1.00 & & & & & & & & \\
\hline 6 & Image & $-.120 *$ & -0.01 & 0.02 & $.165 \#$ & 0.10 & 1.00 & & & & & & & \\
\hline 7 & Enjoyment & -0.04 & 0.00 & -0.01 & $.142 \#$ & 0.02 & $.277 \#$ & 1.00 & & & & & & \\
\hline 8 & Information & -0.10 & 0.00 & -0.01 & 0.09 & 0.00 & $.303 \#$ & $.454 \#$ & 1.00 & & & & & \\
\hline 9 & Emotional & -0.07 & -0.08 & -0.02 & $.157 \#$ & 0.04 & $.354 \#$ & $.331 \#$ & $.387 \#$ & 1.00 & & & & \\
\hline 10 & Performance & 0.00 & -0.04 & 0.01 & -0.04 & $-.156 \#$ & 0.09 & $.324 \#$ & $.312 \#$ & $.282 \#$ & 1.00 & & & \\
\hline 11 & Satisfaction & -0.09 & -0.06 & 0.05 & -0.01 & -0.04 & 0.08 & 0.06 & -0.07 & $.233 \#$ & $.100 *$ & 1.00 & & \\
\hline 12 & Intention & -0.09 & 0.02 & -0.02 & 0.10 & -0.02 & $.348 \#$ & $.591 \#$ & $.547 \#$ & $.377 \#$ & $.413 \#$ & $.124 *$ & 1.00 & \\
\hline 13 & Addiction & -0.03 & -0.04 & 0.00 & 0.08 & 0.05 & 0.09 & 0.02 & $.126^{*}$ & 0.08 & -0.08 & 0.06 & $.106^{*}$ & 1.00 \\
\hline
\end{tabular}

\#. Correlation is significant at the 0.01 level (2-tailed).

*. Correlation is significant at the 0.05 level (2-tailed).

Table 4

Descriptive statistics

\begin{tabular}{|c|c|c|c|c|}
\hline & Mean & SD & Skewness & Kurtosis \\
\hline Perceived image & 2.96 & 0.747 & 0.05 & 0.05 \\
\hline Enjoyment & 3.84 & 0.645 & -.971 & 2.44 \\
\hline Information Value & 3.85 & 0.667 & -.899 & 1.99 \\
\hline Emotional Value & 2.90 & 0.793 & -.088 & -.276 \\
\hline Academic Performance & 3.45 & 0.829 & -.616 & 0.47 \\
\hline Satisfaction & 2.30 & 0.890 & 0.25 & -.512 \\
\hline Continues Intention & 3.46 & 0.663 & -.452 & 0.90 \\
\hline Internet Addiction & 2.98 & 0.897 & -.095 & -.386 \\
\hline
\end{tabular}

\subsection{Hypotheses testing}

To test Hypotheses 1, 2, 3 and 4, multiple linear regression was used where enjoyment, perceived image, information value and emotional value were the independent variables and continued intention was the dependent variable. The normality plot probability indicates that most of the points are along the best-fit line, and the scatter plot produces no pattern. No multicollinearity issue was detected. The collinearity statistics tolerance and variance inflation factor (VIF) was within the limits of $>0.1$ and less than 4 , respectively (Garson, 2012).

Table 5

Regression Analysis results (H1, 2, 3, 4 and 6)

\begin{tabular}{|c|c|c|c|c|c|c|c|c|}
\hline \multirow{2}{*}{$\frac{\text { Outcome }}{\text { Predictors }}$} & \multicolumn{5}{|c|}{$\begin{array}{l}\text { Continuous Intention } \\
\mathrm{H} 1,2,3 \text { and } 4\end{array}$} & \multicolumn{3}{|c|}{$\begin{array}{l}\text { Satisfaction } \\
\text { H6 }\end{array}$} \\
\hline & $\mathrm{B}$ & $\mathrm{t}$ & $\mathrm{p}$ & Tol. & VIF & $\mathrm{B}$ & $\mathrm{t}$ & $\mathrm{p}$ \\
\hline Constant & 0.242 & 1.367 & 0.172 & & & 1.728 & 7.216 & 0.000 \\
\hline Perceived image & 0.104 & 2.847 & 0.005 & 0.83 & 1.204 & & & \\
\hline Enjoyment & 0.404 & 9.159 & 0.000 & 0.755 & 1.325 & & & \\
\hline Information Value & 0.297 & 6.776 & 0.000 & 0.717 & 1.394 & & & \\
\hline Emotional Value & 0.076 & 2.132 & 0.034 & 0.770 & 1.298 & & & \\
\hline \multicolumn{9}{|c|}{ Academic Performance } \\
\hline \multicolumn{9}{|l|}{ Satisfaction } \\
\hline Continues Intention & & & & & & 0.166 & 2.446 & 0.015 \\
\hline \multicolumn{9}{|l|}{ Internet Addiction } \\
\hline $\mathrm{R}$ & 0.686 & & & & & 0.124 & & \\
\hline $\mathrm{R}^{2}$ & 0.47 & & & & & 0.015 & & \\
\hline $\mathrm{F}$ & 84.522 & & & & & 5.981 & & \\
\hline $\mathrm{p}$ & 0.000 & & & & & 0.015 & & \\
\hline
\end{tabular}

The results are shown in Table 5, they indicate that the overall model was significant $(F=84.522, p=0.000<0.05)$, the $R$-value indicates that the whole model is correlated with the dependent (Pallant 2005), $\mathrm{R}=0.686, \mathrm{R}^{2}$ indicates the amount of variance in the dependent variable that is caused by the independent variables (Pallant 2005) $\mathrm{R}^{2}=47 \%$. The adjusted $\mathrm{R}^{2}=46.58 \%$ which is an indicator of the variance caused by the independent variables if the whole population were tested. Hence it provides a better estimation for the population $R^{2}$ value (Pallant 2005), the difference between $R^{2}$ and Adj- $R^{2}$ is 0.005 . Regarding the coefficients, the four independent variables have a significant positive effect on the dependent. Perceived image $\mathrm{B}=0.104$ and $\mathrm{p}=0.005<0.05$, Enjoyment $\mathrm{B}=0.404$ and $\mathrm{p}=0.000<0.05$, Information value $\mathrm{B}=0.297$ and $\mathrm{p}=0.000<0.05$ and finally emotional value $\mathrm{B}=0.076$ and $\mathrm{p}=0.034<0.05$. The weakest effect was for Emotional value. Accordingly, H1, H2, H3 and H4 were supported. To test Hypothesis 6, single linear regression was used were continuous intention to use the internet was entered as an 
independent variable and satisfaction were entered as the dependent variable, results indicated that continues intention has a significant positive effect on satisfaction, the model was significant were $F=5.981, P=0.015<0.05$. $R=0.124, R=1.5 \%$. the adjusted $\mathrm{R}^{2}=1.3 \%$. This indicates that continued intention is not responsible for a high amount of variance in the dependent satisfaction. However, a one-point increase in continued intention will lead to 0.166 point increase in satisfaction $(\mathrm{B}=0.166$, $\mathrm{p}=0.015<0.05$ ). The results are shown in Table 5. To test Hypothesis 8 , single linear regression was used were continuous intention to use the internet was entered as an independent variable and addiction were entered as the dependent variable, results indicated that continues intention has a significant positive effect on Satisfaction, the model was significant were $\mathrm{F}=4.329, \mathrm{P}=0.038<0.05 . \mathrm{R}=0.106, \mathrm{R}^{2}=1.1 \%$. the adjusted $\mathrm{R}^{2}=0.9 \%$. This indicates that continued intention is not responsible for a high amount of variance in the dependent satisfaction. However, a one-point increase in continued intention will lead to 0.143 point increase in satisfaction $(B=0.143, \mathrm{p}=0.015<0.038)$. The results are shown in Table 5 .

Table 6

Regression Analysis results (H5, 7,8 and 9)

\begin{tabular}{|c|c|c|c|c|c|c|c|c|}
\hline \multirow{2}{*}{$\begin{array}{l}\text { Outcome } \\
\text { Predictors }\end{array}$} & \multicolumn{3}{|c|}{$\begin{array}{l}\text { Addiction } \\
\mathrm{H} 8\end{array}$} & \multicolumn{5}{|c|}{$\begin{array}{l}\text { Academic Performance } \\
\mathrm{H} 5, \mathrm{H} 7 \text { and } \mathrm{H} 9\end{array}$} \\
\hline & $\mathrm{B}$ & $\mathrm{t}$ & $\mathrm{p}$ & $\mathrm{B}$ & $\mathrm{t}$ & $\mathrm{p}$ & Tol. & VIF \\
\hline Constant & 2.485 & 10.284 & 0.000 & 1.875 & 7.835 & 0.000 & & \\
\hline \multicolumn{9}{|l|}{ Perceived image } \\
\hline \multicolumn{9}{|l|}{ Enjoyment } \\
\hline \multicolumn{9}{|l|}{ Information Value } \\
\hline \multicolumn{9}{|l|}{ Emotional Value } \\
\hline \multicolumn{9}{|l|}{ Academic Performance } \\
\hline Satisfaction & & & & 0.052 & 1.211 & 0.226 & .982 & 1.018 \\
\hline Continues Intention & 0.143 & 2.081 & 0.038 & 0.525 & 9.008 & 0.000 & 0.975 & 1.026 \\
\hline Internet Addiction & & & & -0.121 & -2.831 & 0.005 & 0.987 & 1.014 \\
\hline $\mathrm{R}$ & 0.106 & & & 0.436 & & & & \\
\hline $\mathrm{R}^{2}$ & 0.011 & & & 0.19 & & & & \\
\hline $\mathrm{F}$ & 4.329 & & & 29.901 & & & & \\
\hline $\mathrm{p}$ & 0.038 & & & 0.000 & & & & \\
\hline
\end{tabular}

To test Hypotheses 5, 7 and 9, multiple linear regression was used where satisfaction, addiction and continuous intentions were the independent variables, and academic performance was the dependent variable. The normality probability plot indicates that most of the points are near the best-fit line, and the scatter plot produces no pattern. No multicollinearity issue was detected. The collinearity statistics tolerance and variance inflation factor (VIF) were within the limits of $>0.1$ and less than 4, respectively (Garson 2012). The results are shown in Table 6, it indicates that the overall model was significant $(\mathrm{F}=29.901$, $\mathrm{p}=0.000<0.05)$, the $\mathrm{R}$-value indicate that the whole model is correlated with the dependent, $\mathrm{R}=0.436, \mathrm{R}^{2}$ indicate the amount of variance in the dependent variable that is caused by the independent variables $\mathrm{R}^{2}=19 \%$. The adjusted $\mathrm{R}^{2}=18.4 \%$, which is an indicator of the variance caused by the independent variables if the whole population were tested, the difference between $\mathrm{R}^{2}$ and Adj- $\mathrm{R}^{2}$ is 0.006 . Regarding the coefficients, the three independent variables have a significant positive effect on the dependent. Satisfaction $\mathrm{B}=0.052$ and $\mathrm{p}=0.226>0.05$, Addiction $\mathrm{B}=-0.121$ and $\mathrm{p}=0.005<0.05$, and finally continues intention $\mathrm{B}=0.525$ and $\mathrm{p}=0.000<0.05$. The weakest effect was for satisfaction. Accordingly, $\mathrm{H} 7$ was not supported while H9 was partially supported, the effect significant but negative. Finally, H5 was supported.

\section{Discussion and Conclusion}

Former research studies have not assessed the relationship between individual drivers and social drivers on Internet usage continuance intention. This study contributes to closing this gap through extending the associations between individual drivers (hedonic value, information value, and emotional value) and social drivers (perceived Image) and examining its impact on Internet continuance intention. In addition, prior research studies have not investigated the negative impact of Internet addiction on students' academic performance. Thus, this study investigates the impact of Internet addiction, satisfaction, and continuance intention on students' academic performance gap. We categorized this research results into two main parts. The first results part related to antecedents of Internet continuance intention. The second results part examined the influence of satisfaction, continuance intention, and Internet addiction influence on university students' academic performance. The analysis results in Table 5 and Table 6 show that the overall model was significant, and the whole model is correlated with the dependents. The first part of the results shows that perceived enjoyment, perceived image, information value, and emotional value explain $47 \%$ of the variance in continuance intention. The second part of the results showed that the independent variables cause $19 \%$ of variances in the dependent variable. Regarding the first part of the results, this study conforms with previous research that perceived enjoyment is a determinant of continuance intention (Chou et al., 2010; Mouakket, 2015; Choi, 2016; Li et al., 2018; Fang \& Liu, 2019). According to Mouakket (2015) and Li et al. (2018), perceived enjoyment influences the users' continuance intention of the social networks sites. In addition, the findings of this research confirmed that perceived image influences students' continuance intention of the Internet. This finding aligned with the finding of other studies that confirmed the perceived image is significantly influenced by continuance intention to use different types of technologies (Mohammadi, 2015; Basak \& Calisir, 2015). Moreover, this research found that information value exhibits a significant influence on continuous intention, which is consistent with Yang et al. (2018). In addition, this research results analysis confirmed the 
positive influence of emotional value on continuous intention. This result is consistent with prior studies that confirmed the emotional value as a motivation to use the technology (Yang \& Lin, 2017; Yang et al., 2018). The analysis results also confirmed the positive influence of Internet usage continuance intention on satisfaction and Internet addiction. Regarding the second part of the results, the results confirmed the significantly negative influence of Internet addiction on the students' academic performance. Internet addiction refers to the excessive use of the Internet due to being psychologically reliant on its use in a way that somewhat hinders other essential actions that the user could perform and, in the process, yielding negative results. This can be justified as the students spend a long time using the Internet; they will waste their time on irrelevant contents to their academic study that negatively affects their academic performance. This finding supports the results of previous research that Internet addiction can lead to a high degree of Internet abuse (Chen et al., 2008). Also, another research study found that smartphone addiction had a negative impact on students' academic performance (Samaha \& Hawi 2016). It was argued earlier that satisfaction, which is how well the service provides fulfilment would positively affect the students' academic performance. Contrary to our expectation, satisfaction was not found to influence students' academic performance. It can be explained as nowadays students use the Internet to access studies related materials with few other alternatives, and their satisfaction from the use of the Internet might be not related to academic performance. Thus, students are using the Internet regardless of their satisfaction and dissatisfaction. Finally, the research results show that continual intention to use the Internet has a significantly positive effect on students' academic performance. This finding supports previous research such as (Sampath Kumar \& Manjunath, 2013) that confirmed the advantages of using the Internet as students. Using the Internet can help students search for information related to their modules and assignments. In addition, using the Internet can help students working together as groups to connect and collaborate online. Many universities nowadays integrate online learning with traditional teaching methods to create more interactive student-centred learning. Another research study showed that Facebook usage increases students' academic performance (Naqshbandi et al., 2017).

To conclude, this study investigated the impact of integrating internal and external factors that influence continuance usage intention of the Internet in students' context. It investigated the effect of perceived enjoinment, perceived image, information value, and emotional value, on continuance intention. The analysis results showed that these four factors are positively influencing the usage continuance intention of the Internet in the context of students. Moreover, the analysis results showed that Internet usage continuation intention significantly and positively influences students' satisfaction and Internet addiction. In addition, this study investigates the role of satisfaction, continuance intention, and Internet addiction on students' academic performance gap. The results showed that while continuance intention positively influences academic performance, Internet addiction negatively influences academic performance in the context of university students. Finally, the analysis results showed that satisfaction does not influence students' academic performance. This research study contributes to the emerging body of knowledge by extending the associations between individual drivers and social drivers of technology adoption and use. It also contributes to the evolving body of knowledge about Internet addiction by giving a theoretical justification and empirical support for the impact of Internet addiction and students' academic performance.

\section{Future Research}

Future research can be applied across different countries to compare the findings taking into consideration contextual factors peculiar for each country or region. In addition, it was mentioned in the limitation section that this research studied a group of university students. Therefore, it can be suggested that future research can investigate other demographic groups, for example employees or students from different year levels (or postgraduates). Moreover, the cultural differences can be addressed in future research to investigate if culture can influence continuance intention and academic performance. Finally, this research only focused on four variables that could influence continuance intention. Moreover, it investigated the impact of satisfaction, Internet addiction, and continuance intention on students' academic performance. Thus, future research can investigate other variables such as privacy and perceived usefulness to enrich the current research.

\section{References}

Al-Fraihat, D., Joy, M., Masa'deh, R., \& Sinclair, J. (2020). Evaluating E-learning systems success: An empirical study. Computers in Human Behavior, 102(June 2019), 67-86. https://doi.org/10.1016/j.chb.2019.08.004

Al-Maghrabi, T., \& Dennis, C. (2011). What drives consumers' continuance intention to e-shopping?: Conceptual framework and managerial implications in the case of Saudi Arabia. International Journal of Retail and Distribution Management, 39(12), 899-926. https://doi.org/10.1108/09590551111183308

Alshurideh, M. T., Al Kurdi, B., Masa'deh, R., \& Salloum, S. A. (2021). The moderation effect of gender on accepting electronic payment technology: a study on United Arab Emirates consumers. Review of International Business and Strategy, ahead-of-p(ahead-of-print). https://doi.org/10.1108/ribs-08-2020-0102

Alzougool, B. (2019). The use and continuance use of social media applications by small and medium enterprises in Kuwait. Global Knowledge, Memory and Communication, 68(6-7), 471-490. https://doi.org/10.1108/GKMC-11-2018-0094

Amoroso, D., \& Lim, R. (2017). The mediating effects of habit on continuance intention. International Journal of Information Management, 37(6), 693-702. https://doi.org/10.1016/j.ijinfomgt.2017.05.003

Anthonysamy, L., Koo, A. C., \& Hew, S. H. (2020). Self-regulated learning strategies and non-academic outcomes in higher education blended learning environments: A one decade review. Education and Information Technologies, 3677-3704. 
https://doi.org/10.1007/s10639-020-10134-2

Authors, F., Susanto, A., Chang, Y., \& Ha, Y. (2016). Determinants of continuance intention to use the smartphone banking services. Industrial Management \& Data Systems. https://doi.org/10.1108/IMDS-05-2015-0195

Bae, M. (2018). Understanding the effect of the discrepancy between sought and obtained gratification on social networking site users' satisfaction and continuance intention. Computers in Human Behavior, 79, 137-153. https://doi.org/10.1016/j.chb.2017.10.026

Bagavadi Ellore, S., Niranjan, S., Brown, U. J., Ellore, S. B., Niranjan, S., \& Brown, U. J. (2014). The Influence of Internet Usage on Academic Performance and Face-to-Face Communication. Journal of Psychology and Behavioral Science, 2(2), 163-186. https://doi.org/10.6007/IJARBSS/v7-i8/3301

Barrett, J. D. (2004). Quality from customer needs to customer satisfaction. Technometrics, 46(1), 118-118. https://doi.org/10.1198/tech.2004.s752

Basak, E., \& Calisir, F. (2015). An empirical study on factors affecting continuance intention of using Facebook. Computers in Human Behavior, 48, 181-189. https://doi.org/10.1016/j.chb.2015.01.055

Bhattacherjee, A. (2014). Understanding information systems continuance: an expectation-confirmation model. MIS Quarterly, 25(3), 351-370.

Bhattacherjee, A., \& Lin, C. P. (2015). A unified model of IT continuance: Three complementary perspectives and crossover effects. European Journal of Information Systems, 24(4), 364-373. https://doi.org/10.1057/ejis.2013.36

Bölen, M. C. (2020). Exploring the determinants of users' continuance intention in smartwatches. Technology in Society, 60. https://doi.org/10.1016/j.techsoc.2019.101209

Busalim, A. H., Masrom, M., Normeza, W., \& Wan, B. (2019). The impact of Facebook Addiction and self-esteem on students , academic performance: A multi-group analysis. Computers \& Education, 142(August), 103651. https://doi.org/10.1016/j.compedu.2019.103651

Çebi, A., \& Güyer, T. (2020). Students' interaction patterns in different online learning activities and their relationship with motivation, self-regulated learning strategy and learning performance. Education and Information Technologies, 39753993. https://doi.org/10.1007/s10639-020-10151-1

Chen, S. C., Chen, H. H., \& Chen, M. F. (2009). Determinants of satisfaction and continuance intention towards self-service technologies. Industrial Management and Data Systems, 109(9), $1248-1263$. https://doi.org/10.1108/02635570911002306

Chen, S. C., Yen, D. C., \& Hwang, M. I. (2012). Factors influencing the continuance intention to the usage of Web 2.0: An empirical study. Computers in Human Behavior, 28(3), 933-941. https://doi.org/10.1016/j.chb.2011.12.014

Chen, J. V., Chen, C. C., \& Yang, H. H. (2008). An empirical evaluation of key factors contributing to internet abuse in the workplace. Industrial Management and Data Systems, 108(1), 87-106. https://doi.org/10.1108/02635570810844106

Chiang, H. S. (2013). Continuous usage of social networking sites: The effect of innovation and gratification attributes. Online Information Review, 37(6), 851-871. https://doi.org/10.1108/OIR-08-2012-0133

Chiu, C. M., \& Huang, H. Y. (2015). Examining the antecedents of user gratification and its effects on individuals' social network services usage: The moderating role of habit. European Journal of Information Systems, 24(4), 411-430. https://doi.org/10.1057/ejis.2014.9

Choi, S. (2016). The flipside of ubiquitous connectivity enabled by smartphone-based social networking service: Social presence and privacy concern. Computers in Human Behavior, 65, 325-333. https://doi.org/10.1016/j.chb.2016.08.039

Chou, S. W., Min, H. T., Chang, Y. C., \& Lin, C. T. (2010). Understanding continuance intention of knowledge creation using extended expectation-confirmation theory: An empirical study of Taiwan and China online communities. Behaviour and Information Technology, 29(6), 557-570. https://doi.org/10.1080/01449290903401986

Davis, F. D., Bagozzi, R. P., \& Warshaw, P. R. (1992). Extrinsic and Intrinsic Motivation to Use Computers in the Workplace. Journal of Applied Social Psychology, 22(14), 1111-1132. https://doi.org/10.1111/j.1559-1816.1992.tb00945.x

Emeka, U. J., \& Nyeche, O. S. (2016). Impact of Internet Usage on the Academic Performance of Undergraduates Students: A case study of the University of Abuja, Nigeria. International Journal of Scientific \& Engineering Research, 7(10), 10181029. http://www.ijser.org

Fang, L., \& Liu, Q. (2019). Mobile SNS addiction and user continuance: an empirical investigation of wechat. Tehnicki Vjesnik, 26(4), 1104-1111. https://doi.org/10.17559/TV-20190315145418

Gao, L., Bai, X., \& Authors, F. (2014). An empirical study on continuance intention of mobile social networking services: Integrating the IS success model, network externalities and flow theory. Asia Pacific Journal of Marketing and Logistics, 26(2), 168-189. https://doi.org/10.1108/APJML-07-2013-0086

Garson, G. D. (2012). Testing statistical assumptions: Blue Book Series. Asheboro: Statistical Associate Publishing. https://www.researchgate.net/profile/Jurandy_Penitente-

Filho/post/What is the best statistical method to correlate immunohistochemestry and rtpcr/attachment/59 d $\overline{6} 1 \mathrm{~d} \overline{9} 879197 \mathrm{~b} 80779 \overline{7} 853 \mathrm{c} / \mathrm{AS}: 2 \overline{7} 1755204 \overline{7} 71424 @ 144180289782 \overline{5} / \mathrm{download} /$ assumptions.pdf

Hair, J., Black, W., Babin, B., \& Anderson, R. (2014). Multivariate Data Analysis. Pearson custom library. https://doi.org/10.1038/259433b0

Harrington, D. (2009). Confirmatory Factor Analysis. Confirmatory Factor Analysis. Oxford University Press. https://doi.org/10.1093/acprof:oso/9780195339888.001.0001

Hou, R., Han, S., Wang, K., \& Zhang, C. (2021). To WeChat or to more chat during learning? The relationship between WeChat and learning from the perspective of university students. Education and Information Technologies, 26(2), 1813- 
1832. https://doi.org/10.1007/s10639-020-10338-6

Houghton, D., Pressey, A., \& Istanbulluoglu, D. (2020). Who needs social networking? An empirical enquiry into the capability of Facebook to meet human needs and satisfaction with life. Computers in Human Behavior, 104(September 2019), 106153. https://doi.org/10.1016/j.chb.2019.09.029

Huang, Y. M. (2020). Students' continuance intention toward programming games: hedonic and utilitarian aspects. International Journal of Human-Computer Interaction, 36(4), 393-402. https://doi.org/10.1080/10447318.2019.1647665

Jin, X. L., Christy, M. K. C., Matthew, K. O. L., \& Chen, H. P. (2007). Understanding the sustainability of virtual communities in China. Proceedings of the 15th European Conference on Information Systems, ECIS 2007, 310-321.

Joorabchi, S. H., Hassan, T. N., \& Hassan, M. A. (2011). Internet usage among female undergraduates in Ferdowsi University, Iran. SEARCH Journal of the Southeast Asia Research Centre for Communications and Humanities, 3(2), 1-20.

Kang, M. (2018). Active users' knowledge-sharing continuance on social Q\&A sites: motivators and hygiene factors. Aslib Journal of Information Management, 70(2), 214-232. https://doi.org/10.1108/AJIM-09-2017-0207

Kang, M. (2019). Dual paths to continuous online knowledge sharing: a repetitive behavior perspective. Aslib Journal of Information Management, 72(2), 159-178. https://doi.org/10.1108/AJIM-05-2019-0127

Karnik, M., Oakley, I., Venkatanathan, J., Spiliotopoulos, T., \& Nisi, V. (2013). Uses \& gratifications of a facebook media sharing group. Proceedings of the ACM Conference on Computer Supported Cooperative Work, CSCW, 821-826. https://doi.org/10.1145/2441776.2441868

Kim, B. (2011). Understanding antecedents of continuance intention in social-networking services. Cyberpsychology, Behavior, and Social Networking, 14(4), 199-205. https://doi.org/10.1089/cyber.2010.0009

Kim, Ki Hun, Kim, K. J., Lee, D. H., \& Kim, M. G. (2019). Identification of critical quality dimensions for continuance intention in mHealth services: Case study of onecare service. International Journal of Information Management, 46(March 2018), 187-197. https://doi.org/10.1016/j.ijinfomgt.2018.12.008

Kim, Kyoung Hwan. (2010). Understanding the consistent use of internet health information. Online Information Review, 34(6), 875-891. https://doi.org/10.1108/14684521011099388

$\mathrm{Ku}$, Y. C., Chen, R., \& Zhang, H. (2013). Why do users continue using social networking sites? An exploratory study of members in the United States and Taiwan. Information and Management. https://doi.org/10.1016/j.im.2013.07.011

Kuan-Yu, L., \& Hsi-Peng, L. (2011). Why people use social networking sites: An empirical study integrating network externalities and motivation theory. Computers in Human Behavior, 27(3), $1152-1161$. https://doi.org/10.1016/j.chb.2010.12.009

Kuo, Y. F., Wu, C. M., \& Deng, W. J. (2009). The relationships among service quality, perceived value, customer satisfaction, and post-purchase intention in mobile value-added services. Computers in Human Behavior, 25(4), 887-896. https://doi.org/10.1016/j.chb.2009.03.003

Lee, Y., \& Kwon, O. (2011). Intimacy, familiarity and continuance intention: An extended expectation-confirmation model in web-based services. Electronic Commerce Research and Applications, 10(3), 342-357. https://doi.org/10.1016/j.elerap.2010.11.005

Leong, L. Y., Hew, T. S., Ooi, K. B., Lee, V. H., \& Hew, J. J. (2019). A hybrid SEM-neural network analysis of social media addiction. Expert Systems with Applications, 133, 296-316. https://doi.org/10.1016/j.eswa.2019.05.024

Li, H., Li, L., Gan, C., Liu, Y., Tan, C. W., \& Deng, Z. (2018). Disentangling the factors driving users' continuance intention towards social media: A configurational perspective. Computers in Human Behavior, 85, 175-182. https://doi.org/10.1016/j.chb.2018.03.048

Liao, Z., \& Shi, X. (2017). Web functionality, web content, information security, and online tourism service continuance. Journal of Retailing and Consumer Services, 39, 258-263. https://doi.org/10.1016/j.jretconser.2017.06.003

Locke, E. A. (1976). The nature and causes of job satisfaction. Handbook of Industrial and Organizational Psychology, $1297-$ 1349.

Ma, L., \& Lee, C. (2012). News sharing in social media: The effect of gratifications and prior experience. Computers in $\begin{array}{lll}\text { Human Behavior, 331-339. } & \text { 28(5), }\end{array}$ http://avoserv.library.fordham.edu/login?url=http://search.ebscohost.com/login.aspx?direct=true\&db=edselp\&AN=S074 756321100210X\&site=eds-live

Maqableh, M., Jaradat, M., \& Azzam, A. (2021). Exploring the determinants of students' academic performance at university level: The mediating role of internet usage continuance intention. Education and Information Technologies. https://doi.org/10.1007/s10639-021-10453-y

Marengo, D., Poletti, I., \& Settanni, M. (2020). The interplay between neuroticism, extraversion, and social media addiction in young adult Facebook users : Testing the mediating role of online activity using objective data. Addictive Behaviors, 102(October 2019), 106150. https://doi.org/10.1016/j.addbeh.2019.106150

Matson, Z., Donmez, B., Savan, B., Photiadis, D., Farahani, E., \& Dafoe, J. (2012). Social drivers of technology adoption and use in the workplace productivity context. In Proceedings of the Human Factors and Ergonomics Society (pp. 21032107). https://doi.org/10.1177/1071181312561446

Mccamey, R., Wilson, B., \& Shaw, J. (2015). Internet Dependency and Academic Performance. The Journal of Social Media in Society, 4(1), 126-150.

Melone, N. P. (1990). A theoretical assessment of the user-satisfaction construct in information systems research. Management Science, 36(1), 76-91. https://doi.org/10.1287/mnsc.36.1.76

Miyazaki, A. D., \& Fernandez, A. (2001). Consumer perceptions of privacy and security risks for online shopping. Journal 
of Consumer Affairs, 35(1), 27-44. https://doi.org/10.1111/j.1745-6606.2001.tb00101.x

Mohammadi, H. (2015). Social and individual antecedents of m-learning adoption in Iran. Computers in Human Behavior, 49, 191-207. https://doi.org/10.1016/j.chb.2015.03.006

Moqbel, M., \& Kock, N. (2018). Unveiling the dark side of social networking sites: Personal and work-related consequences of social networking site addiction. Information and Management, 55(1), 109-119. https://doi.org/10.1016/j.im.2017.05.001

Mouakket, S. (2015). Factors influencing continuance intention to use social network sites: The Facebook case. Computers in Human Behavior, 53, 102-110. https://doi.org/10.1016/j.chb.2015.06.045

Naqshbandi, M. M., Ainin, S., Jaafar, N. I., \& Mohd Shuib, N. L. (2017). To Facebook or to Face Book? An investigation of how academic performance of different personalities is affected through the intervention of Facebook usage. Computers in Human Behavior, 75, 167-176. https://doi.org/10.1016/j.chb.2017.05.012

Nepomuceno, M. V., Laroche, M., \& Richard, M. O. (2014). How to reduce perceived risk when buying online: The interactions between intangibility, product knowledge, brand familiarity, privacy and security concerns. Journal of Retailing and Consumer Services, 21(4), 619-629. https://doi.org/10.1016/j.jretconser.2013.11.006

Obeidat, Z. M. I., Xiao, S. H., Iyer, G. R., \& Nicholson, M. (2017). Consumer revenge using the internet and social media: An examination of the role of service failure types and cognitive appraisal processes. Psychology and Marketing, 34(4), 496-515. https://doi.org/10.1002/mar.21002

Odel, C. O. M., \& Bhattacherjee, A. (2001). Understanding information systems continuance: an expectation-confirmation model. MIS Quarterly, 25(3), 351-370.

Ofosu-Ampong, K., Boateng, R., Anning-Dorson, T., \& Kolog, E. A. (2020). Are we ready for Gamification? An exploratory analysis in a developing country. Education and Information Technologies, 25(3), 1723-1742. https://doi.org/10.1007/s10639-019-10057-7

Oliver, R. L., \& Gerald, L. (1981). Effect of satisfaction and its antecedents on consumer preference and intention. Advances in Consumer Research, 8(1), 88-93. https://doi.org/10.1086/466442

Pai, C. K., Wang, T. W., Chen, S. H., \& Cai, K. Y. (2018). Empirical study on Chinese tourists' perceived trust and intention to use biometric technology. Asia Pacific Journal of Tourism Research, 23(9), 880-895. https://doi.org/10.1080/10941665.2018.1499544

Pallant, J. (2005). SPSS Survival Guide - A step by step guide to data analysis using SPSS for Windows. Journal of Advanced Nursing. Chicago: Illinois: Open University Press.

Patwardhan, P., Yang, J., \& Patwardhan, H. (2011). Understanding media satisfaction: Development and validation of an affect-based scale. Atlantic Journal of Communication, 19(3), 169-188. https://doi.org/10.1080/15456870.2011.584508

Pelling, E. L., \& White, K. M. (2009). The theory of planned behavior applied to young people's use of social networking Web sites. Cyberpsychology \& behavior: the impact of the Internet, multimedia and virtual reality on behavior and society, 12(6), 755-9. https://doi.org/10.1089/cpb.2009.0109

Podsakoff, P. M., \& Organ, D. W. (1986). Self-Reports in Organizational Research: Problems and Prospects. Journal of Management, 12(4), 531-544. https://doi.org/10.1177/014920638601200408

Revels, J., Tojib, D., \& Tsarenko, Y. (2010). Understanding consumer intention to use mobile services. Australasian Marketing Journal, 18(2), 74-80. https://doi.org/10.1016/j.ausmj.2010.02.002

Ronis, D. L., Yates, J. Frank., \& Kirscht, J. P. (1989). Attitudes, decisions, and habits as determinants of repeated behavior. Attitude Structure and Function, 213-239. https://books.google.com/books?hl=es\&lr=\&id=fiOvSm50Z7kC\&pgis=1

Saari, L. M., \& Judge, T. A. (2004). Employee attitudes and job satisfaction. Human Resource Management, $43(4), 395-407$. https://doi.org/10.1002/hrm.20032

Salam, M., \& Farooq, M. S. (2020). Does sociability quality of web-based collaborative learning information system influence students' satisfaction and system usage? International Journal of Educational Technology in Higher Education, 17(1). https://doi.org/10.1186/s41239-020-00189-z

Samaha, M., \& Hawi, N. S. (2016). Relationships among smartphone addiction, stress, academic performance, and satisfaction with life. Computers in Human Behavior, 57, 321-325. https://doi.org/10.1016/j.chb.2015.12.045

Sampath Kumar, B. T., \& Manjunath, G. (2013). Internet use and its impact on the academic performance of university teachers and researches A comparative study. Higher Education, Skills and Work-based Learning, 3(3), 219-238. https://doi.org/10.1108/HESWBL-09-2011-0042

Sheth, J.N., Newman, B.I., \& Gross, B.L. (1991). Why we buy what we buy: a theory of consumption values. Journal of Business Research, 22(2), $159-170$.

Shiau, W. L., \& Luo, M. M. (2013). Continuance intention of blog users: The impact of perceived enjoyment, habit, user involvement and blogging time. Behaviour and Information Technology, 32(6), 570-583. https://doi.org/10.1080/0144929X.2012.671851

Skog, B. (2009). Mobiles and the Norwegian teen: identity, gender and class. Perpetual Contact, $255-273$. https://doi.org/10.1017/cbo9780511489471.020

Statista. (2021). Daily social media usage worldwide 2012-2020 Published by H. Tankovska, Feb 8, 2021 How much time do people spend on social media? As of 2019 and 2020, the average daily social media usage of internet users worldwide amounted to 145 minutes per day, up fr. https://www.statista.com/statistics/433871/daily-social-media-usage-worldwide/

Sun, Y., Liu, L., Peng, X., Dong, Y., \& Barnes, S. J. (2014). Understanding Chinese users' continuance intention toward online social networks: An integrative theoretical model. Electronic Markets, 24(1), 57-66. 
https://doi.org/10.1007/s12525-013-0131-9

Turel, O., Serenko, A., \& Bontis, N. (2010). User acceptance of hedonic digital artifacts: A theory of consumption values perspective. Information and Management, 47(1), 53-59. https://doi.org/10.1016/j.im.2009.10.002

Valaei, N., \& Baroto, M. B. (2017). Modelling continuance intention of citizens in government Facebook page: A complementary PLS approach. Computers in Human Behavior, 73, 224-237. https://doi.org/10.1016/j.chb.2017.03.047

Wang, C., Teo, T. S. H. H., \& Liu, L. (2020). Perceived value and continuance intention in mobile government service in China. Telematics and Informatics, 48(January), 101348. https://doi.org/10.1016/j.tele.2020.101348

Wang, H.-Y., Liao, C., \& Yang, L.-H. (2013). What Affects Mobile Application Use? The Roles of Consumption Values. International Journal of Marketing Studies, 5(2). https://doi.org/10.5539/ijms.v5n2p11

Wang, X., Goh, D. H. L., \& Lim, E. P. (2020). Understanding continuance intention toward crowdsourcing games: A longitudinal investigation. International Journal of Human-Computer Interaction, 36(12), 1168-1177. https://doi.org/10.1080/10447318.2020.1724010

Wei, H. L., Lin, K. Y., Lu, H. P., \& Chuang, I. H. (2015). Understanding the intentions of users to stick to social networking sites: A case study in Taiwan. Behaviour and Information Technology, 34(2), 151-162. https://doi.org/10.1080/0144929X.2014.928745

Yang, H.-L., \& Lin, C.-L. (2014). Why do people stick to Facebook web site? A value theory-based view. Information Technology and People, 27(1), 21-37. https://doi.org/10.1108/ITP-11-2012-0130

Yang, H. L., \& Lin, R. X. (2017). Determinants of the intention to continue use of SoLoMo services: Consumption values and the moderating effects of overloads. Computers in Human Behavior, 73, 583-595. https://doi.org/10.1016/j.chb.2017.04.018

Yang, S., Jiang, H., Yao, J., Chen, Y., \& Wei, J. (2018). Perceived values on mobile GMS continuance: A perspective from perceived integration and interactivity. Computers in Human Behavior, 89(June), 16-26. https://doi.org/10.1016/j.chb.2018.07.032

Yang, X. (2019). Social influence or personal attitudes?: Understanding users' social network sites continuance intention. Kybernetes, 48(3), 424-437. https://doi.org/10.1108/K-05-2018-0223

Yin, F. S., Liu, M. L., \& Lin, C. P. (2015). Forecasting the continuance intention of social networking sites: Assessing privacy risk and usefulness of technology. Technological Forecasting and Social Change, 99, 267-272.

Zhang, C. B., Li, Y. N., Wu, B., \& Li, D. J. (2017). How WeChat can retain users: Roles of network externalities, social interaction ties, and perceived values in building continuance intention. Computers in Human Behavior, 69, $284-293$. https://doi.org/10.1016/j.chb.2016.11.069

Zhao, L., \& Lu, Y. (2012). Enhancing perceived interactivity through network externalities: An empirical study on microblogging service satisfaction and continuance intention. Decision Support Systems. https://doi.org/10.1016/j.dss.2012.05.019

Zheng, Y., Zhao, K., \& Stylianou, A. (2013). The impacts of information quality and system quality on users' continuance intention in information-exchange virtual communities: An empirical investigation. Decision Support Systems, 56(1), 513524. https://doi.org/10.1016/j.dss.2012.11.008

Zhou, T. (2015). The effect of network externality on mobile social network site continuance. Program, 49(3), $289-304$. https://doi.org/10.1108/PROG-10-2014-0078

Zong, W., Yang, J., \& Bao, Z. (2019). Social network fatigue affecting continuance intention of social networking services: The case of WeChat users in China's universities. Data Technologies and Applications, 53(1), $123-139$. https://doi.org/10.1108/DTA-06-2018-0054

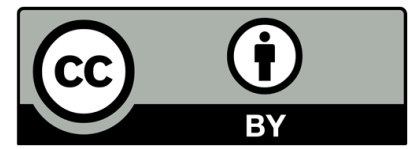

(C) 2021 by the authors; licensee Growing Science, Canada. This is an open access article distributed under the terms and conditions of the Creative Commons Attribution (CC-BY) license (http://creativecommons.org/licenses/by/4.0/). 